Available online at GSC Online Press Directory

GSC Biological and Pharmaceutical Sciences

e-ISSN: 2581-3250, CODEN (USA): GBPSC2

Journal homepage: https://www.gsconlinepress.com/journals/gscbps

(Mini REVIEW ARTICle)

\title{
Covid-19 pandemic: Is it tip of the iceberg?
}

\author{
Kajal S ${ }^{1 *}$ and Anam A ${ }^{2}$ \\ 1 Department of Otorhinolaryngology and Head-Neck Surgery, All India Institute of Medical Sciences, New Delhi, India. \\ 2 Department of Gastroenterology, All India Institute of Medical Sciences, New Delhi, India.
}

Publication history: Received on 19 June 2020; revised on 25 June 2020; accepted on 27 June 2020

Article DOI: https://doi.org/10.30574/gscbps.2020.11.3.0193

\begin{abstract}
The current COVID-19 pandemic has affected our daily lives and routine to a large extent. Be it our over-burdened health related services or fear of economic loss on a larger scale, this pandemic has affected everyone in some way or the other. No doubt that those getting infected with this virus are being affected the most but still there is a huge population which is not infected with this virus. This group of population is suffering due to its pre-existing illness/disease which is not being addressed currently because of various unavoidable measures like lockdown taken up by many governments across the world. This stratum of population may be hidden as of now but it will eventually pop-out when the current pandemic gets over or is slowed down and this may lead to another health crisis post COVID-19 pandemic.
\end{abstract}

Keywords: COVID-19; Coronavirus; pandemic; public health

\section{Introduction}

Coronavirus disease 2019 (COVID-19) caused by Severe acute respiratory syndrome coronavirus - 2 (SARS-CoV-2) was declared a pandemic by World Health Organization (WHO) on March 11, 2020. It has affected daily lives of both infected and non-infected people in many ways. Both developed and the developing world countries are finding ways to cope up with the economic losses due to this pandemic. It has exposed how crippled our health infrastructure is to fight with such sudden outbreaks. In the US, uninsured healthcare workers who are predisposed to an increased risk of viral infection may lead to significant financial consequences in the event of illness (1). Preventive measures like Lockdown and social distancing have heightened fears of increasing domestic violence, which includes physical, emotional and sexual abuse (2). But all this may only be the tip of the iceberg of upcoming health care related crisis which many countries in the world may face after this pandemic is over.

The mortality rate of COVID-19 is 2-3\% (3). Many people who do not have COVID-19 but have other long-standing illnesses with higher mortality rate, if not treated, are hidden portion of the iceberg. Patients with an early stage cancer may progress to a higher stage if not treated on time or may even become incurable. This stands true especially in developing nations where such patients wait for long time for their definitive treatment; be it elective surgery, chemotherapy or any other definitive procedure. Patients waiting for an elective surgical procedure may develop disease related complication and present to emergency department of already over-burdened hospitals and thus adding to morbidity. Patients already living with disease related morbidity do not know when they will receive a definitive treatment and this can have psychological impact on both the patient and his/her family.

Many international health bodies have come up with the guidelines to manage different cases pertaining to their specialty and categorizing them as urgent, semi-urgent or elective procedures $(4,5)$. But even if a case is non-urgent as of now; it may become urgent if the current pandemic and restrictions continue for a longer time. This will again add

\footnotetext{
${ }^{*}$ Corresponding author: Kajal S
}

Copyright (C) 2020 Author(s) retain the copyright of this article. This article is published under the terms of the Creative Commons Attribution Liscense 4.0. 
morbidity or even mortality in some cases. This holds true not only for developing countries who already have poor health resources and infrastructure but also for over-burdened health care of developed countries during this pandemic.

It will be difficult to manage such cases once the countries ease their lockdown policies when all these hidden cases explode in out-patient departments and demand urgent care as they must have already suffered a lot due to their disease even if not infected with COVID-19. Will the health authorities continue this categorization of those who require urgent care and those who do not? Will they be compelled to make different guidelines to handle post COVID-19 health crisis? How will the hospitals adjust all such patients who had to wait for their elective surgery because of this pandemic? Will it increase corruption in health care services of under-developed countries where only those who have contacts with higher authorities in hospital get a priority treatment?

All these questions must be addressed early before we land up in another health service crisis post COVID-19 pandemic.

\section{Conclusion}

COVID-19 pandemic has affected all of us in one way or the other irrespective of whether one has been infected by this novel virus or not. It has brought huge changes in working of health sector. The whole world is focused on treating and preventing spread of COVID-19. This has affected other health services like regular outpatient clinics, elective surgeries, routine health checkup for those suffering from chronic medica conditions, etc. The health policy makers need to think about these services as well because if they are not taken care of along with managing novel Coronavirus pandemic they may cause another health crisis when things start to settle down post this pandemic.

\section{Compliance with ethical standards}

\section{Acknowledgments}

None

Disclosure of conflict of interest

None

\section{References}

[1] Nicola M, Alsafi Z, Sohrabi C, et al. (2020). The Socio-Economic Implications of the Coronavirus and COVID-19 Pandemic: A Review [published online ahead of print, 2020 Apr 16]. Int J Surg.

[2] Coronavirus: Domestic abuse calls up 25\% since lockdown, charity says - BBC News [Internet]. [cited $2020 \mathrm{Apr}$ 7].

[3] Sahu KK, Mishra AK and Lal A. (2020). COVID-2019: update on epidemiology, disease spread and management. Monaldi Arch Chest Dis, 16, 90(1).

[4] Liu Z, Zhang Y, Wang X, et al. (2020). Recommendations for Surgery During the Novel Coronavirus (COVID-19) Epidemic [published online ahead of print, 2020 Apr 11]. Indian J Surg, 1-5.

[5] Kowalski, LP, Sanabria, A, Ridge, JA, et al. (2020). COVID-19 pandemic: Effects and evidence-based recommendations for otolaryngology and head and neck surgery practice. Head \& Neck, 1- 9.

\section{How to cite this article}

Kajal S and Anam A. (2020). Covid-19 pandemic: is it tip of the iceberg? GSC Biological and Pharmaceutical Sciences, 11(3), 224-225. 